\title{
Evolving roles of circadian rhythms in liver homeostasis and pathology
}

\author{
Dexi Zhou ${ }^{1,2, *}$, Yaqin Wang ${ }^{1,2, *}$, Lu Chen ${ }^{1,2}$, Leijuan Jia ${ }^{1,2}$, Jie Yuan ${ }^{1,2}$, Mei Sun ${ }^{1,2}$, \\ Wen Zhang ${ }^{1,2}$, Peipei Wang ${ }^{1,2}$, Jian Zuo ${ }^{1,2}$, Zhenyu Xu ${ }^{1,2}$, Jiajie Luan ${ }^{1,2}$ \\ ${ }^{1}$ Laboratory of Clinical Pharmacy of Wannan Medical College, Wuhu, Anhui Province, China \\ ${ }^{2}$ Department of Pharmacy in Yijishan Hospital of Wannan Medical College, Wuhu, Anhui Province, China \\ * The authors have contributed equally to this paper \\ Correspondence to: Jiajie Luan, email: Ivanjiajie757@163.com \\ Dexi Zhou, email: zhoudexiahmu@163.com \\ Keywords: circadian rhythms, liver metabolism, epigenetic modifications, liver fibrosis, hepatocellular carcinoma \\ Received: October 14, $2015 \quad$ Accepted: January 18, $2016 \quad$ Published: January 28, 2016
}

\section{ABSTRACT}

Circadian clock in mammals is determined by a core oscillator in the suprachiasmatic nucleus (SCN) of the hypothalamus and synchronized peripheral clocks in other tissues. The coherent timing systems could sustain robust output of circadian rhythms in response to the entrainment controlled environmentally. Disparate approaches have discovered that clock genes and clock-controlled genes (CCGs) exist in nearly all mammalian cell types and are essential for establishing the mechanisms and complexity of internal time-keeping systems. Accumulating evidence demonstrates that the control of homeostasis and pathology in the liver involves intricate loops of transcriptional and post-translational regulation of clock genes expression. This review will focus on the recent advances with great importance concerning clock rhythms linking liver homeostasis and diseases. We particularly highlight what is currently known of the evolving insights into the mechanisms underlying circadian clock. Eventually, findings during recent years in the field might prompt new circadian-related chronotherapeutic strategies for the diagnosis and treatment of liver diseases by coupling these processes

\section{INTRODUCTION}

Circadian rhythms are generated by an endogenous molecular pacemaker [1], arising from an adaptation of 24-hour light-dark (LD) cycle derived from the earth's rotation [2]. They are capable of generating oscillatory behavior independent of external factors, for example light intensity/temperature-entrainable cues [3-5]. Further evidence supports that circadian clock programs multiple behavioral and physiological processes, such as metabolism, growth, development and other functions of diverse organisms 1s $[6,7]$. that Nevertheless, the disturbance of circadian rhythms appears to trigger the loss of homeostasis throughout the body because of the altered oscillation of different clock genes and CCGs $[8$, 9].

At the cellular and molecular levels, the circadian clock consists of many oscillators that form the feedback timing circuit. Specifically, autoregulatory negative feedback loops have been observed in mammals [10], which is commonly controlled by the crosstalk between positive and negative clock components [11]. These oscillators programme the 24-hour rhythms which are crucial for maintaining various cells and tissues-specific functions [12]. In fact, the molecular clock in all organisms shares some defined characteristics and mechanisms, including transcription/translation, post-transcriptional and post-translational modifications in regulating the feedback cycles $[13,14]$. Notably, local metabolic rhythms represent an output of tissue-based circadian clocks, together with various cells characteristics [15]. Clinical and experimental animals studies have uncovered that considerable $\mathrm{s}$ genes, proteins and enzymes levels in livers are controlled by circadian rhythms to a great extent [1618]. Tong et al. previously performed a systematic review to estimate the contribution of circadian rhythms to the liver physiology and diseases [19]. This would explain the findings, such as a reprogramming of the liver metabolism 
and transcription pathways observed in the experimental subjects with loss of circadian rhythms [20].

This review attempts to summarize the recent observations with emphasis on the potential mechanisms underlying the regulation of liver-specific circadian clock. We will clarify how circadian clocks have incorporated the clock-generating machinery into the robust output of liver circadian rhythmicity from physiology to pathology. Hopefully, this could shed light on the development of some novel therapeutic and diagnostic targets of liver diseases on the basis of circadian-related chronotherapeutic strategies.

\section{THE COMMON STRUCTURE OF THE CIRCADIAN PACEMAKER}

The timing of daily rhythms in anticipation of the light-dark cycle is based mainly on the circadian clock synchronizes behavioral and physiological processes. It is clearly suggested that circadian rhythms can be modified by external events, includingLD cycle, temperature changes or availability of food [21-23]. Simulated daily body temperature rhythms of mice and humans are the importantly external cues in resetting and synchronizing the peripheral oscillators [24]. The impacts of temperature changes on the plant circadian clock have been observed in Arabidopsis thaliana, which could influence the clock genes expression [25]. Accumulating studies have found that some complex networks in part mediating the interplay between different clock genes by using several pharmacological or genetic interventions [26]. Growing evidence suggests an interlocked transcription-translation feedback loop as the molecular mechanism to drive circadian clock [27]. This feedback circuit is composed of a series of core clock genes, which are divided into positive elements/promoters including circadian locomotor output cycles kaput (CLOCK), brain and muscle Arnt-like protein 1 (BMAL1), and negative elements/repressors including three period (PER1, 2 and 3) and two cryptochromes (CRY1 and 2) molecules [28]. CLOCK and BMAL1 are two subunits of the heterodimeric basic-helix-loop-helixPAS (PER-ARNT-SIM domain)-containing transcription factors (TFs). Firstly, the CLOCK and BMAL1 proteins dimerize, bind to the E-boxes (CACGTG) nucleotide sequences in the promoter of downstream targets, including the clock genes and CCGs, and thereby activates the transcription of PER and CRY. Then, PER and CRY are translated in the cytoplasm and form the PER-CRY complexes, which eventually translocate from the cytosol to the nucleus and inhibit CLOCK-BMAL1-dependent transcription activity. Importantly, the phosphorylation and ubiquitination of the negative elements leads to the low levels and degradation of PER and CRY [29, 30], in turn, allowing the positive elements at a high level to restart the new cycle. Thus, the imbalance of the production and degradation of PER and CRY either lengthens or shortens the circadian period of the clock in mammals. On the other hand, there is an alternative loop comprised by accessory proteins or nuclear receptors (NRs), including the retinoic acid-related orphan receptors (ROR $\alpha, \beta$ and $\gamma$ ) and REVERB orphan receptor family (REV-ERB $\alpha$ and $\beta)[31,32]$. $\mathrm{ROR} \alpha$ and $\mathrm{REV}-\mathrm{ERB} \alpha$ compete for the ROR response element (RORE) binding site in the BMAL1 promoter, REV-ERB $\alpha$ firstly accumulates quickly and inhibits BMAL1 transcription, then RORA, which accumulates more slowly and activates BMAL1 transcription, reinforce stability and robust rhythmicity of the internal clock systems [33].Moreover, the mechanisms employed for mammalian circadian control are increasingly observed by additional post-transcriptional regulation and epigenetic modifications, apart from the classic transcriptiontranslation pattern, which will be elucidated as following section.

In summary, these data suggest that proper functioning of the circadian system determined by the orchestration of a central clock in the SCN and synchronized peripheral clocks in local tissues, with emphasis on multiple regulatory mechanisms in response to the environmental changes (Figure 1).

\section{MOLECULAR MECHANISMS CONTROLLING CIRCADIAN RHYTHMS}

The molecular clocks in mammals are existed not only in the central pacemaker neurons of SCN, but also in almost all peripheral tissues. Analysis of central and peripheral clock mechanisms has received considerable evidence that the circadian behavior is controlled at both transcriptional and post-transcriptional levels, including cellular pathways [34], TFs [35], epigenetic changes [36] and post-transcriptional regulators [37], as reviewed recently [38]. Such regulation alone or in combination has been shown to predominantly alter the phase and amplitude of rhythmic mRNA and protein expression in the liver microenvironment [39].

In the past few years, it has been rapidly uncovered that cellular signaling pathways responsible for coupling physiological and metabolic cues to the molecular clock [40]. The mTOR signaling pathway is strictly linked with the metabolic processes and nutrient avialibility in livers [41].By the intermittently intraperitoneal injections(i.p.) of rapamycin(inhibitor of $\mathrm{mTOR}$ ), the weight gain is largely prevented in mice on high-fat diet (HFD) than other schedules [42]. According to the Khapre et al.' results, mTOR complex 1 (mTORC1) activity oscillation was controlled by the feeding-entrainable clock mechanism confirmed by the time-resticeted (TR) feeding schedule [43]. Moreover, they further indicated that increased activity of mTORC1 signaling owing to the BMAL1 deficiency and BMAL1-dependent mTOR up-regulated mechanisms were associated with the accelerated aging [44].In addition, many studies have also suggest connetions 
between cellular signal transduction and circadian cycles. For example, the insulin-phosphatidylinositol 3-kinase (PI3K)-and Forkhead box class O3 (FOXO3)-dependent signaling are required for protecting circadian rhythmicity in the liver and modulating hepatic metabolic function via transcriptional regulation of CLOCK [45]. Furthermore, a series of core clock and output genes (BMAL1, ARNTL and PER1,2) have been identified with the anti-tumor effects which are subject to the regulation through a nongenetic route, e.g. epigenetic changes [46].

Epigenetic modifications, including DNA methylation, non-coding RNAs and histone modifications, have been implicated to hamper the transcription and post-transcription of target genes expression, including circadian genes. Recent advances in genomic technologies have allowed researches of determining methylation of $\mathrm{CpG}$ dinucleotides in the promoter sequence of circadian genes. Notably, the variability of individual timing system of daily circadian behavior is influenced by environmental changes, such as the prolonged or shortened light-dark cycle, which is driven by global alterations in promoter DNA methylation in the SCN [47]. Paired specimens from the cancerous and noncancerous tissues indicate the possible disruption of the promoter DNA methylation of circadian clock genes in the development of tumorigenesis [48]. Particularly, accumulating evidences have shown that miRNAs function as the direct and indirect modulators which are the significant players in regulating various aspects of circadian clock function [49]. Finally, a variety of histone modifications patterns, for example, histone lysine demethylase JARIDa, deacetylase SIRT1, have a nonredundant role in keeping circadian oscillator function $[50,51]$. The relationship between epigenetic genetics and circadian rhythms may promote the understanding of

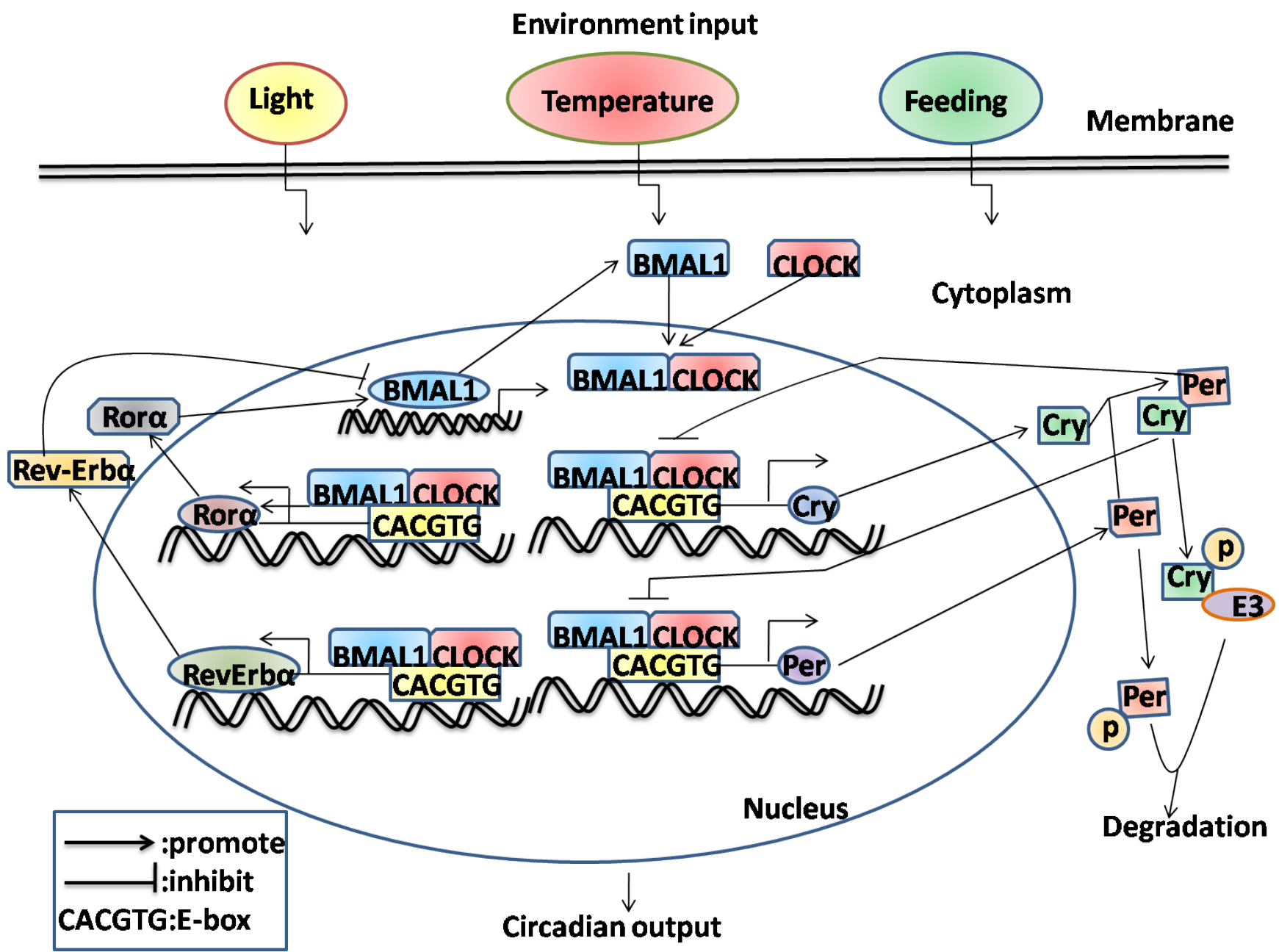

Figure 1: Schematic representation of molecular interactions in mammalian circadian transcriptional negative feedback loops. For simplicity, many cells and tissues have the capacity to oscillate with a wide variety of periodicities, and the circadian oscillators can be entrained to local time in response to environmental stimuli including daylight, temperature and feeding availability. Firstly, the interactions between positive elements (BMAL1 and CLOCK) and negative elements (CRY and PER) which form the interconnect negative feedback loop in mammals through inhibiting CLOCK-BMAL1-dependent transcription. Then, ROR $\alpha$ and Rev-ERB $\alpha$, which form the secondary loop that regulates rhythms, resulting from the activation and inhibition the expression of BMAL1, respectively. Finally, phosphorylation and ubiquitination of the negative components results in their eventual degradation, allowing the positive components to restart the cycle. 
mammalian health and diseases.

\section{CIRCADIAN RHYTHMS IN LIVER HOMEOSTASIS AND METABOLISM}

Liver is a primary target involved in the regulation of several key metabolic parameters including the levels of glucose, lipid, bile acid and other aspects of physiology $[52,53]$. Circadian clocks are endogenous oscillators, driving the rhythmic expression of a broad array of clock genes and CCGs, and circadian misalignment can evoke the disparate pathologies of liver [9, 54]. Emerging evidence indicates a more integral mechanism for the coordination of circadian rhythm in orchestrating liver metabolism and physiology $[55,56]$.

Glucose and lipid metabolism as the major output of the circadian clock in mice liver, are associated with a dynamic protein-DNA interactome by targeting BMAL1 [57]. Adiponectin, a well-recognized antidiabetic adipokine, is involved in glucose and lipid metabolism, which more recently has been reported to be activated by BMAL1 and CLOCK through the transcriptional activity of peroxisome proliferator-activated receptor $\gamma$ (PPAR- $\gamma$ ) and its co-activator $1 \alpha(\mathrm{PGC}-1 \alpha)$ [58]. It protects from impeded insulin signaling due to some crucial signaling molecules including insulin receptor substrates (IRS) in the liver [59]. Adiponectin metabolic pathway components and expression of clock genes in liver exhibit circadian rhythmicity under low-fat diet [60], however, fasting and high-fat diet lead to phase advance and delay, respectively. Consequently, high-fat diet correlates with the malfunction of circadian rhythm, which may lead to the development of hepatic insulin resistance and obesity $[61,62]$. In turn, insulin is a major regulator of FOXO activity, which is the TFs of CLOCK, indicating the insulin-FOXO3-CLOCK signaling pathway is critical for the modulation of circadian rhythms [45]. Likewise, the insulin-mTORC2AKT signaling promotes the de novo lipogenesis through regulating the hepatic metabolic function of BMAL1 [63]. Hence, we could infer that hepatic circadian clock systems are highly responsive to internal cues, such as insulin metabolism [64]. The impact of circadian rhythms on hepatic metabolism has been implicated in mice with genetic deletion of different clock genes. Male PER1/2/3 triple-deficient mice gain significantly more body mass than wild-type controls on high-fat diet [65]. Similarly, knockout of the two CRY genes (CRY1, 2) in mice causes the altered dimorphic liver metabolism, along with disruption of sex-specific liver products and growth hormone (GH) [66]. Lipidomic analysis reveals circadian oscillations of hepatic triglyceride (TAG) levels, but its phases and levels are completely different in clockdisrupted or nighttime restricted feeding mice [67]. Given the deposition of excess TAG within hepatocytes as a hallmark of nonalcoholic fatty liver disease (NAFLD), indicating the NAFLD is obviously associated with a loss of circadian rhythm. Currently, many studies demonstrate circadian clock controls hepatic metabolism mostly at the transcriptional level by synchronizing the expression of liver enzymes [68]. For example, mice deficient in Nocturnin, a gene that encodes a circadian deadenylase, have deficits in lipid metabolism or uptake and changes in glucose and insulin sensitivity [69]. Remarkably, Nocturnin has been shown to enhance PPAR- $\gamma$ activity [70], which is recommended at the center of a regulatory loop between circadian networks and metabolic output. It is also interesting to note that leucine-rich repeatcontaining $G$ protein-coupled receptor 4 is a new regulator for energy metabolism and mutant $\mathrm{Lgr}^{\mathrm{m}} \mathrm{m}$ mice show altered rhythms of TAG and cholesterol [68]. In addition, mice lacking a secondary $12 \mathrm{hr}$ period rhythm characterized by rhythmic activation of the IRE1 $\alpha$ pathway in the endoplasmic reticulum (ER), which leads to the deregulation of ER-resident enzymes and perturbed lipid metabolism through the aberrant sterol responsive element binding protein (SREBP) [71]. Conversely, fibroblast growth factor 21 (FGF-21), a hormone exists in liver and fat, dose dependently reduces body weight and hepatic steatosis is largely associated with inhibition of nuclear SREBP-1 [72]. Gain-and loss-of-function studies in mice hepatocytes showed that hepatic FGF21 levels are suppressed by the expression of PGC-1 $\alpha$, which is dependent on REV-ERB $\alpha$ and the ligand ALAS1 expression [73]. Similar to PGC-1 $\alpha$, PGC-1 $\beta$ knockout mice develop abnormal circadian activity, hepatic steatosis and increased serum TAG and cholesterol levels induced by high-fat feeding [74]. These results highlight the role of PGC- $1 \alpha / \beta$ play in directing hepatic energy metabolism via the circadian-controlled manner. The CLOCK gene influences the circadian rhythms of hepatic glycogen synthesis through transcriptional activation of glycogen synthase 2 (Gys2) [75]. Eventually, sleep disruption significantly abolishes liver clock rhythms and dramatically alters hepatic bile acid (BA) metabolism by suppressing Cyp7A1 expression [76], which is correlated with the inhibited activity of TFs including hepatocyte nuclear factor $4 \alpha(\mathrm{HNF} 4 \alpha)$ and D-site binding protein (Dbp). However, the krüppel-like factor (KLF)15and FGF15 signaling axis promotes and inhibits the circadian BA production, respectively, which is identified as a nonhepatic basis for regulation [77].

Recent evidence indicates that epigenetic regulation appears to be participate in the circadian regulation of liver metabolism [78]. The histone H3-lysine-4 methyltransferase mixed-lineage leukemia 3 (MLL3) and its closest homolog, MLL4 complexes, named MLL3/4 complexes, function as major epigenetic regulators and pivotal coactivators of the circadian TFs, ROR- $\alpha$ and $-\gamma$, in the hepatic circadian control of BA production [79]. The $\mathrm{NAD}^{+}$-dependent protein deacetylase, sirtuin 1(SIRT1), is involved in regulating hepatic insulin sensitivity via CLOCK/BMAL1-dependent manner [80]. 
Table 1: Circadian rhythms control hepatic metabolism and physiology

\begin{tabular}{|c|c|c|c|c|}
\hline Substance & Function & Regulatory genes & Mechanisms & References \\
\hline Adiponectin & Antidiabetic adipokine & $\begin{array}{l}\text { Bmal1, Clock, } \\
\text { Ppar- } \gamma, \text { Pgc-1 } \alpha\end{array}$ & Transcriptional & {$[58-60]$} \\
\hline Triglyceride & Energy storage & $\begin{array}{l}\text { Nocturnin, Lgr4, Ppar- } \\
\text { Fgf-21, Pgc-1 } \alpha \text { and } \beta \text {, } \\
\text { Srebp-1, Sirt1, miR-122 } \\
\text {, HDAC3 }\end{array}$ & $\begin{array}{l}\text { Transcriptional, } \\
\text { Epigenetics }\end{array}$ & $\begin{array}{l}{[63,67-74,85,} \\
87,88]\end{array}$ \\
\hline Glucose & Energy supply & Bmal1,Clock, Gys 2 & Transcriptional & {$[75]$} \\
\hline Insulin & $\begin{array}{l}\text { Antidiabetic } \\
\text { hormone }\end{array}$ & Bmal1,Clock,Sirt1 & $\begin{array}{l}\text { Transcriptional, } \\
\text { Epigenetics }\end{array}$ & {$[80]$} \\
\hline Bile acids & $\begin{array}{l}\text { Facilitate digestion } \\
\text { and absorption }\end{array}$ & $\begin{array}{l}\text { Cyp } 7 A 1, H N F 4 \alpha, \quad D b p, \\
M L L 3 / 4\end{array}$ & $\begin{array}{l}\text { Transcriptional, } \\
\text { Epigenetics }\end{array}$ & {$[76,77,79]$} \\
\hline
\end{tabular}

SIRT1 prevents obesity-induced hepatic steatosis by regulating lipid homeostasis through positively binding PPAR- $\alpha$ and coactivator PGC-1 $\alpha$ [81]. Therefore, we might have a hypothesis that SIRT1-mediated PPAR- $\alpha$ / PGC-1 $\alpha$ signaling pathway links the regulation of receptors like REV-ERB $\alpha$ [73]. As expected, the action and oscillation of NRs in liver may contribute to circadian entrainment of nutrient and energy metabolism [74, 82]. REV-ERB $\alpha$ and $\beta$ are highly coordinated for protecting both clock and metabolic functions [83], dual depletion of them by creating double-knockout mice profoundly disrupts circadian expression of core circadian clock and lipid homeostatic gene networks [84]. The liver-specific microRNA, miR-122, has been found to be the major circadian transcriptional target of REV-ERB $\alpha$ [85]. As a result, miR-122 has emerged as key contributor of liver homeostasis and energy metabolism by the circadiandependent manner, such as miR-122 inhibits circadian Nocturnin expression [86]. Genetic disruption of the NRs corepressor (NCOR) 1- histone deacetylase (HDAC) 3 interaction in mice causes aberrant regulation of clock genes and results in abnormal circadian and metabolic behaviour [87]. Furthermore, genomic recruitment of HDAC3 by REV-ERB $\alpha$ displays a circadian rhythm gene expression that is required for normal lipid homeostasis in mice liver [88].

Herein, although the advances in understanding of the circadian clocks controlling the rhythmic expression of a large number of genes involves in hepatic metabolism and homeostasis, further investigation remains to be necessary for clarifying the mechanisms of clockcontrolled output systems in liver(Table 1).

\section{CIRCADIAN RHYTHMS IN LIVER INJURY AND FIBROSIS}

The liver is frequently exposed to diverse insults, such as chemicals, alcohol, viral infection and metabolic disorders [89-91]. Although it could regenerate after acute injury, chronic liver damage causes fibrosis and cirrhosis.
Liver fibrosis is a common scarring response to all forms of chronic liver injury [92], which can result in the increased extracellular matrix (ECMs) protein production by the activated hepatic stellate cells (HSCs) [93]. There is increasing evidence to support that the disruption of circadian rhythm is a critical molecular mechanism in the pathogenesis from organic injury to fibrosis [94-96]. Previous researches indicated that the liver expressed a diverse set of genes in a circadian manner [97] and the different genes functions were under direct or indirect circadian control [98]. Importantly, the regulatory structure that governs circadian dynamics within the liver at a transcriptional level has been uncovered by using bioinformatics analysis [97].

Elevated results in the induction of multiple liver injury responses support circadian rhythms are correlated with the magnitude of hepatic damage. Chemotherapeutic agent cyclophosphamide is known to have the anti-cancer toxicity in liver,whereas selenium compounds show protective roles agnist it by modulation of the molecular time-keeping system through the up-regualtion of BMAL1 expression [99].Chronic alcohol exposure damages core properties of the circadian clock system which confers vulnerability to alcohol-induced pathology in liver [100, 101]. Utilizing genetically or environmentally circadian disruption models, such as CLOCK mutant and shifted LD cycle mice with chronic alcohol consumption, numerous reports demonstrate that circadian disruption promotes alcohol-induced intestinal hyperpermeability, endotoxemia and steatohepatitis possibly in part by increasing tight junction protein occludin $[102,103]$. Analysis of circadian gene expression in ethanol-induced liver injury shows that the extent of injury is associated with the variations of hepatic circadian genes PER1 [104]. PER1 appears to regulate expression of the endothelin axis genes including endothelin-1 (ET-1), two receptors endothelin-A $\left(\mathrm{ET}_{\mathrm{A}}\right)$ and endothelin-B $\left(\mathrm{ET}_{\mathrm{B}}\right)$ in a time-dependent manner in liver [105]. ET-1 correlates with liver function and injury, which might enhance the nitric oxide (NO) production and the blood flow in the hepatic sinusoids [106]. Lipopolysaccharide (LPS) inhibits the ET-1-induced 
NO production and disrupts liver microcirculation, this process could be blocked by the Rho-kinase (ROCK-2) inhibition in the liver sinusoidal endothelial cells [107]. In addition, LPS-induced liver injury is greater during the early active than the early resting period, followed by dosing-time-dependent variation in the accumulation of polymorphonuclear cells (PMN) and subsequent IL-6 production [108]. The PER2 gene is also an important component of liver circadian system and the deficiency of PER2 induces the liver injury and fibrosis during cholestasis [96]. PER2 may function in diurnal variation of acetaminophen (APAP) induced hepatotoxicity via modulating Cyp1 A2 expression in mice [109]. However, the amplitude of PER2 is not remarkably changed in fibrotic livers, which totally infer that PER2 gene rhythmic expression could be an important contribution mechanism to liver fibrogenesis [110]. Similarly, PER2 decreases carbon tetrachloride $\left(\mathrm{CCl}_{4}\right)$-induced hepatotoxicity via the suppression of uncoupling protein-2 (Ucp2) expression that depends on a CLOCK-controlled PPAR- $\alpha$ signal transduction pathway in mice [111]. The mechanisms of $\mathrm{CCl}_{4}$ toxicity in rat livers are suggested to be caused through a Cyp2E1-dependent chronotoxicity [112]. In line, further study suggests that loss of PER2 predisposes liver fibrosis by increasing HSC activation and inhibiting HSC apoptosis via the TRAIL-R2/DR5 pathway [113]. As expected, these findings are paralleled by enhanced levels of several key fibrogenesis gene (TGF- $\beta_{1}$, TNF- $\alpha$, TIMP-1) expressions in PER2 ${ }^{-/}$mice that have undergone $\mathrm{CCl}_{4}$ treatment and bile duct ligation (BDL) $[96,113]$. Collectively, these findings provides a variety of direct or indirect evidence of the association between the PER $1 / 2$ and liver fibrogenesis. TGF- $\beta /$ Smads-dependent transcriptional signaling is the important intracellular mediator in the development of liver fibrosis [114]. Notably, the Smad3 is expressed in a circadian rhythmmanner in mice liver, which depending on CLOCK/ BMAL1 [115]. These findings suggests that the TGF- $\beta /$ Smads signaling pathway shows the circadian expression and leads to the fibrogenesis.

Interestingly, clock genes BMAL1, CLOCK and CRY2, along with two important clock-regulated genes PPAR- $\alpha$ and Cyp450 lose daily rhythms and their mRNA levels are significantly decreased in the fibrotic mice induced by $\mathrm{CCl}_{4}$ [110]. The two important hepatic metabolic genes PPAR- $\alpha$ and Cyp450 [116] are significantly impaired during liver fibrogenesis [110], which imply that alterations of hepatic clock genes lead to the changes of many physiologically metabolic parameters (e.g. lipid and drug metabolism). Indeed, the circadian clock controls most metabolic pathways in liver by regulating the metabolism-related genes expression in a cyclic fashion $[68,117]$. Circadian clocks represent relevant targets to consider for optimization of therapeutic schedules of cyclin-dependent kinases (CDK) inhibitors through the clock-controlled detoxification pathways
[118].

REV-ERB $\alpha$, a heme-sensing NRs, is involved in metabolic and circadian pathways [119], further suggesting that its up-regulation is a conserved response in activated HSCs and injured livers independent of etiology [120]. Cytoplasmic expression of REV-ERB $\alpha$ was an intrinsic profibrogenic response characterized by the increased fibrogenic markers in activated HSCs [120]. However, it may also have potential antifibrotic functions by repressing the expression and circadian output plasminogen activator inhibitor-1 (PAI-1) through binding the promoter of PAI-1 [121], a coagulation regulator that promotes fibrosis [122]. In line, CLOCK is involved in PAI-1 gene expression and PER2 represses PAI-1 gene transcription in a BMAL1/2-dependent manner [123, 124]. Hence, REV-ERB $\alpha$ is a bifunctional regulator for exhibiting either anti-or profibrogenic effects, depending on milieu. Additionally, REV-ERB $\alpha$ is believed to act as the transcriptional repressor of BMAL1 [125], and the induction of innate immune challenge of macrophages by LPS is conditionally altered by the miR-155/BMAL1/NF$\kappa \mathrm{B}$ axis [126]. LPS and some Toll-like receptors (TLRs) in various cell types, such as HSCs and macrophages, involving in the regulation of liver inflammation and fibrosis [127-129], future researches will continue to focus on expanding our understanding of whether circadiancontrolled mechanisms lie it (Figure 2, 3).

\section{CIRCADIAN RHYTHMS IN LIVER CANCER}

Hepatocellular carcinoma (HCC) is one of the most common causes of cancer-related death in worldwide, which molecular pathogenesis is extremely complex and heterogeneous [130, 131]. Evolving information suggests that the incidence and mortality of $\mathrm{HCC}$ are expected to rise since the increasingly metabolic syndrome with NAFLD, in addition to viral hepatitis and alcohol-induced liver diseases [130]. In view of the link between disrupted circadian rhythms and NAFLD has been extensively investigated [132, 133], it is of interest to explore the functions and mechanisms of circadian clock involved in HCC.

Several lines of evidence have established functional correlation between the disruption of circadian rhythms and carcinogenesis [134]. For instance, oscillatory genes have the ability to influence the different etiology of cancers, including cell proliferation [135], apoptosis [136], cell cycle control [137], DNA damage response [138] and treatment sensitivity of chemotherapy agents and radiation in cancers $[139,140]$. In these backgrounds of divergent cancer types [141-143], observations from cell/ animal models and clinical patients have revealed that the expression profiles of circadian genes are quite different between the cancerous and noncancerous samples. In particular, many avenues of research have provided the 

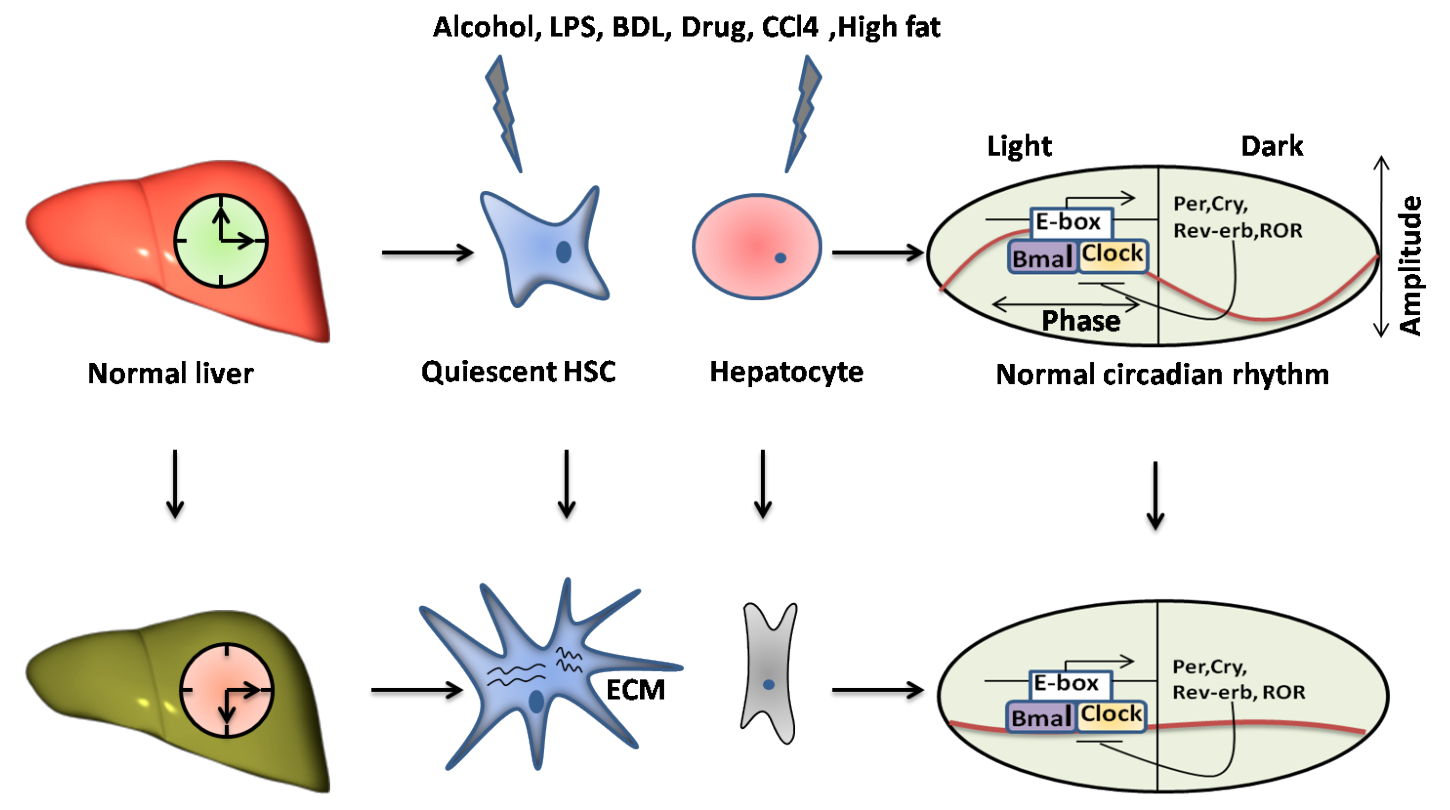

Injured and fibrotic liver

Activated HSC Injuryed hepatocyte

Disrupted circadian rhythm

Figure 2: The disruption of circadian rhythms exists in the liver injury and fibrosis. The livers undergo the variously chronic damages, such as alcohol, LPS, BDL, drug, $\mathrm{CCl}_{4}$ and high fat, leading to the liver injury and fibrosis characterized by the activation of $\mathrm{HSCs}$ and the hepatocytes injury, apoptosis or death. Particularly, it could disrupt the circadian rhythm in livers through causing misalignment of the amplitude and phase of a normal rhythm in key cell types, such as HSCs and hepatocytes.

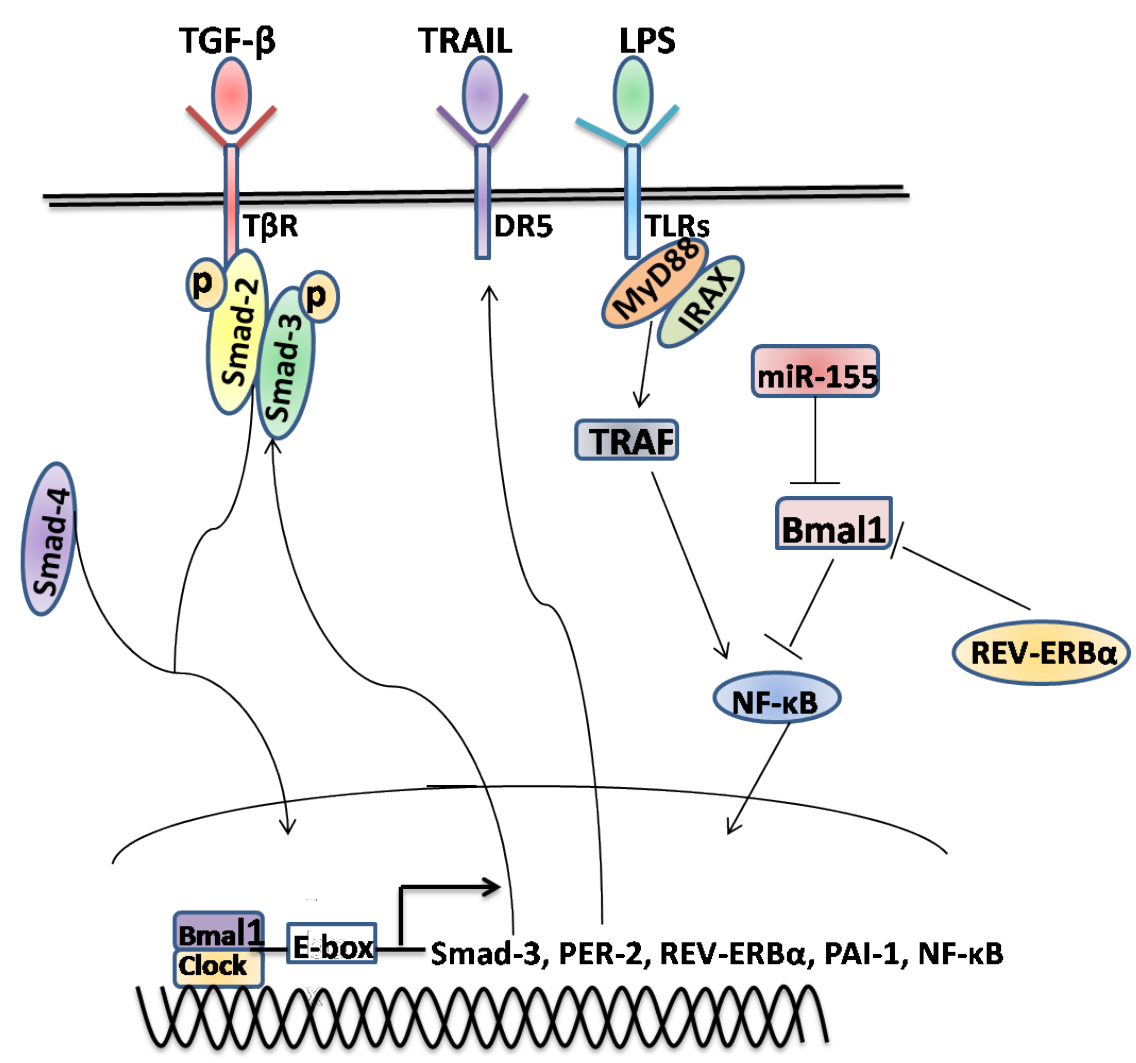

Figure 3: The molecular mechanisms involved in the manipulation of the circadian rhythms in hepatic stellate cell. Several of the key signaling pathways, for example TGF- $\beta$ /Smad, TRAIL/DRs and LPS/TLRs, might either directly or indirectly interact with the circadian rhythms in HSCs via regulating the transcription of core clock genes and other CCGs. In addition, the epigenetic modifications, such as miR-155, might be also involved in the rhythmic genes expression. Some other conditions have not yet been described need further study to investigate. 
Table 2: Characteristics of various circadian genes involved in hepatocellular carcinoma

\begin{tabular}{|l|l|l|l|}
\hline Genes & Expression & Function and regulatory mechanisms & References \\
\hline Bmal1 & $\downarrow$ & Influence cell cycle & {$[149]$} \\
\hline Bmal2 & $\downarrow$ & $\begin{array}{l}\text { Inhibition of cell proliferation and cell cycle; Induction of } \\
\text { apoptosis }\end{array}$ & {$[144]$} \\
\hline Clock & $\downarrow$ & HULC & {$[151]$} \\
\hline Per1 & $\downarrow$ & Methylation, HULC & {$[146,149,151]$} \\
\hline Per2 & $\downarrow$ & Counteract HCV replication; tumor size $(>3 \mathrm{~cm})$ & {$[146,147,149]$} \\
\hline Per3 & $\downarrow$ & Overexpression of EZH2, tumor size $(>3 \mathrm{~cm})$ & {$[146,149]$} \\
\hline Cry1 & $\downarrow$ & Induction of cell apoposis, Methylation & {$[148,151]$} \\
\hline Cry2 & $\downarrow$ & Induction of cell apoposis & {$[146,148]$} \\
\hline CKI $\varepsilon$ & $\downarrow$ & EZH2 & {$[149]$} \\
\hline Tim & $\downarrow$ & tumor grade & {$[149]$} \\
\hline
\end{tabular}

tantalizing suggestion that hepatocarcinogenesis might directly or indirectly undergo a series of interactions with the circadian clock that can account for oscillator function. A number of mechanisms may explain the circadian control on HCC, firstly, a down-regulated gene, BMAL2 in HCC may exert the effect of inhibiting the cell proliferation, in turn, overexpression of antisense BMAL2 results in reduced cell cycle time and TNF- $\alpha$-induced increment of CPP32/caspase-3 activity, and a concomitantly increased $\mathrm{G} 2 / \mathrm{S}$ phase transition of cells [144]. An increased risk for the development of HCC is closely associated with chronic hepatitis B virus (HBV) infection [145]. Recently, it has identified that the mRNA expression levels of the PER1, 2 and 3 and CRY2 genes in HCC tissue are significantly decreased [146], which might be disrupted by the HBV X protein $(\mathrm{HBx})$. Moreover, the circadian protein PER2 could counteract HCV replication [147], it is therefore supported the hypothesis that mutual effect between viral infection and clock gene machinery which might be implicated in the HCC. Furthermore, mutation of CRY in p53-null mice delays the onset of cancer by sensitizing TNF- $\alpha$-initiated apoptosis through interfacing with the GSK $3 \beta$ kinase and alleviating prosurvival NF$\kappa \mathrm{B}$ signaling [148]. In consistent, early study observed the decreased levels of both RNA and protein of the BMAL1, CLOCK, PER1, 2, 3, Cry2, CKIs and TIM genes in HCC cells in comparison to their noncancerous counterpart cells [149]. Down-regulation of these circadian genes is likely to be caused by several non-genetic factors, including promoter methylation, overexpression of EZH2 or other factors, which is tightly associated with the disturbance of cell cycle, tumor size and tumor grade [149]. These results in agreement with previous studies that epigenetic silencing modifications, such as DNA hyper-methylation and histone $\mathrm{H} 3$ acetylation, are responsible for restraining clock genes expression in the tumorigenesis [150]. Thus, differentially methylated or acetylated genes in HCC as compared to normal samples whether contributing to the circadian clock system need further study to confirm it. Coincidentally, a long noncoding RNA (lncRNA), is highly upregulated in liver cancer (HULC) and believed to contribute to the acceleration of hepatocarcinogenesis through disturbing circadian rhythm of CLOCK and its downstream circadian oscillators, such as PER1 and CRY1 [151]. In other words, down-regulation of several clock genes results in disturbance of circadian rhythm in HCC, which may disrupt the control of the central pacemaker and benefit selective survival of cancerous cells and promote carcinogenesis [152].

Recent data have shown that liver-specific overexpression of ET1 in the zebrafish causes the HCC [153], owing to the disruption of liver clock to some extent [105]. ET1 is significantly up-regulated in HBx-induced HCC in mice [154], whether it influences the circadian rhythm in this process is a major objective in future research. Hepatic metastases of C26 colon carcinoma with a disrupted circadian rhythm phase shift liver tissue clocks, which might contribute to fatigue and sleep disorders in cancer patients [155]. Hypoxia-inducible factor (HIF) $-1 \alpha$ and HIF- $2 \alpha$ in a hypoxic microenvironment may contribute to the disturbance in the expression of circadian genes in HCC [156]. In addition, genetic variants in circadian genes are significantly associated with susceptibility and prognosis in cancer patients [143]. For example, a single functional polymorphism of PER3 gene (one SNP rs2640908) is significantly associated with increased overall survival in HCC patients treated with transcatheter arterial chemoembolization TACE [157]. This finding from the candidate gene association study provides further confirmation of the role of circadian biomarkers in HCC patients, although warranting further confirmation and mechanistic investigation of other circadian biomarkers in HCC tumorigenesis. Surprisingly, hepatoma is differentially sensitive to circadian timing signals than in healthy tissue in the regard of restricting food availability of daily timed meals [158]. However, on the other hand, controlling mealtiming might be used to increase the efficacy of treatment by many therapeutic cytotoxic drugs $[158,159]$.

The circadian disruption caused by long-term shift work also increases the risk of the development of HCC. In experimental models of shift-work, circadian 
clock disruption from chronic jet-lag (CJL) significantly downregulates p53 and upregulated c-Myc [160], thus favoring cellular proliferation in mice exposed to the hepatic carcinogen, diethylnitrosamine (DEN). Based on these results, it might bring to light the clock genes as circadian biomarkers which are indispensable for the molecular mechanism of hepatocarcinogenesis (Table 2).

\section{CONCLUDING REMARKS}

Given the importance of internal pacemaker in modulating liver-specific rhythmic programs [161], studies have been increasingly carried out to delineate some new regulatory components of circadian function. As a result, it has provided some novel descriptions of previously unidentified mechanisms by which the circadian clock controls the disparate liver diseases [162]. For example, unlike PER1 and 2, PER3 is not indicated to be necessary for the circadian operation, however, it has been largely accepted that PER3 might correlate with circadian regulation $[163,164]$. The robust output of liver circadian clock is derived by the orchestration between central oscillator in SCN and liver-specific local clocks, involving autoregulatory feedback loops and other uncharacterized processes [165, 166]. We highlight the effects of various signaling pathways, TFs and epigenetic mechanisms with the potential to alter the expressions and functions of classic core clock genes and clock-controlled factors at the transcriptional, post-translational and other levels in liver steady-state conditions and diseases. Althoughmolecular mechanisms in relation to circadian rhythms warrant further investigation, they might provide new insights into the development of some chronotherapeutics-dependent approaches to the liver diseases.

\section{Abbreviations}

SCN, suprachiasmatic nucleus ; CCGs, clockcontrolled genes; CLOCK, circadian locomotor output cycles kaput; BMAL1, brain and muscle Arnt-like protein 1; PER, period; CRY, cryptochromes; NRs, nuclear receptors; ROR, retinoic acid-related orphan receptors; REV-ERB, retinoic acid receptor-related orphan nuclear receptor gene; RORE, ROR response element; TFs, transcription factors; PI3K, phosphatidylinositol 3-kinase; FOXO3, forkhead box class O3; PPAR, peroxisome proliferator-activated receptor; IRS, insulin receptor substrates; GH, growth hormone; TAG, triglyceride; NAFLD, nonalcoholic fatty liver disease; ER, endoplasmic reticulum; SREBP, sterol responsive element binding protein; FGF, fibroblast growth factor; Gys2, glycogen synthase 2; BA, bile acid; HNF4 $\alpha$, hepatocyte nuclear factor $4 \alpha$; Dbp, D-site binding protein; KLF, krüppel-like factor; MLL, methyltransferase mixed-lineage leukemia; SIRT1, sirtuin 1; miR, microRNA; HDAC, histone deacetylase; ECMs, extracellular matrix; HSCs, hepatic stellate cells; LD, light:dark ; ET-1, endothelin-1; LPS, lipopolysaccharide; PMN, polymorphonuclear cells; APAP, acetaminophen; Ucp2, uncoupling protein-2; CDK, cyclin-dependent kinases; PAI-1, plasminogen activator inhibitor-1; HCC, hepatocellular carcinoma; HBV, hepatitis B virus; HBx, HBV X; lncRNA, long noncoding RNA; HULC, highly upregulated in liver cancer; HIF, hypoxia-inducible factor; CJL, chronic jet-lag; DEN, diethylnitrosamine .

\section{ACKNOWLEDGMENTS}

All the authors contributed to the concept, design, and writing of this paper. JJL and DXZ contributed to the concept and design of the figures and tables. All authors read, reviewed and approved the final manuscript. This work was supported by grants from Science Foundation of Anhui province(NO:KJ2014A 262);Foundatin for Young Talents in College of Anhui province (NO:2010SQRL175); Cultivation fund project of key scientific research of Wannan Medical College (NO:WK2013ZF02).

\section{CONFLICTS OF INTEREST}

The authors declare no conflict of interest.

\section{REFERENCES}

1. Lee IT, Chang AS, Manandhar M, Shan Y, Fan J, Izumo M, Ikeda Y, Motoike T, Dixon S, Seinfeld JE. Neuromedin s-producing neurons act as essential pacemakers in the suprachiasmatic nucleus to couple clock neurons and dictate circadian rhythms. Neuron. 2015; 85:1086-1102.

2. Edgar RS, Green EW, Zhao Y, van Ooijen G, Olmedo M, Qin X, Xu Y, Pan M, Valekunja UK, Feeney KA. Peroxiredoxins are conserved markers of circadian rhythms. Nature. 2012; 485:459-464.

3. Vanin S, Bhutani S, Montelli S, Menegazzi P, Green EW, Pegoraro M, Sandrelli F, Costa R, Kyriacou CP. Unexpected features of Drosophila circadian behavioural rhythms under natural conditions. Nature. 2012; 484:371375.

4. Lee Y, Montell C. Drosophila TRPA1 functions in temperature control of circadian rhythm in pacemaker neurons. J Neurosci. 2013; 33:6716-6725.

5. Whalley K. Circadian rhythms: Temperature training. Nat Rev Neurosci. 2013; 14:380-380.

6. Chang YG, Cohen SE, Phong C, Myers WK, Kim YI, Tseng R, Lin J, Zhang L, Boyd JS, Lee Y, Kang S, Lee D, Li S, et al. Circadian rhythms. A protein fold switch joins the circadian oscillator to clock output in cyanobacteria. Science. 2015; 349:324-328.

7. DeWoskin D, Myung J, Belle MD, Piggins HD, Takumi 
T, Forger DB. Distinct roles for GABA across multiple timescales in mammalian circadian timekeeping. Proc Natl Acad Sci U S A. 2015; 112:E3911-3919.

8. Asher G, Schibler U. Crosstalk between components of circadian and metabolic cycles in mammals. Cell Metab. 2011; 13:125-137.

9. Reddy AB , Rey G. Metabolic and nontranscriptional circadian clocks: eukaryotes. Annu Rev Biochem. 2014; 83:165-189.

10. Tamayo AG, Duong HA, Robles MS, Mann M and Weitz CJ. Histone monoubiquitination by Clock-Bmall complex marks Per1 and Per2 genes for circadian feedback. Nat Struct Mol Biol. 2015; 22:759-766.

11. Partch CL, Green CB, Takahashi JS. Molecular architecture of the mammalian circadian clock. Trends Cell Biol. 2014; 24:90-99.

12. Scheiermann C, Kunisaki Y, Frenette PS. Circadian control of the immune system. NatRev Immunol. 2013; 13:190198.

13. Masri S, Sassone-Corsi P. The circadian clock: a framework linking metabolism, epigenetics and neuronal function. Nat Rev Neurosci. 2013; 14:69-75.

14. Gallego M, Virshup DM. Post-translational modifications regulate the ticking of the circadian clock. Nat Rev Mol Cell Biol. 2007; 8:139-148.

15. Huang W, Ramsey KM, Marcheva B , Bass J. Circadian rhythms, sleep, and metabolism. J Clin Invest. 2011; 121:2133-2141.

16. Reddy AB, Karp NA, Maywood ES, Sage EA, Deery M, O’Neill JS, Wong GK, Chesham J, Odell M, Lilley KS, Kyriacou CP , Hastings MH. Circadian orchestration of the hepatic proteome. Curr Biol. 2006; 16:1107-1115.

17. Davidson AJ, Castanon-Cervantes O, Stephan FK. Daily oscillations in liver function: diurnal vs circadian rhythmicity. Liver Int. 2004; 24:179-186.

18. Reddy AB, Maywood ES, Karp NA, King VM, Inoue Y, Gonzalez FJ, Lilley KS, Kyriacou CP , Hastings MH. Glucocorticoid signaling synchronizes the liver circadian transcriptome. Hepatology. 2007; 45:1478-1488.

19. Tong X, Yin L. Circadian rhythms in liver physiology and liver diseases. Compr Physiol. 2013; 3:917-940.

20. Eckel-Mahan KL, Patel VR, de Mateo S, Orozco-Solis R, Ceglia NJ, Sahar S, Dilag-Penilla SA, Dyar KA, Baldi P, Sassone-Corsi P. Reprogramming of the circadian clock by nutritional challenge. Cell. 2013; 155:1464-1478.

21. Arble DM, Bass J, Laposky AD, Vitaterna MH, Turek FW. Circadian timing of food intake contributes to weight gain. Obesity. 2009; 17:2100-2102.

22. Buhr ED, Yoo S-H, Takahashi JS. Temperature as a universal resetting cue for mammalian circadian oscillators. Science. 2010; 330:379-385.

23. Zhang Y, Liu Y, Bilodeau-Wentworth D, Hardin PE, Emery P. Light and temperature control the contribution of specific DN1 neurons to Drosophila circadian behavior.
Curr Biol. 2010; 20:600-605.

24. Saini C, Morf J, Stratmann M, Gos P, Schibler U. Simulated body temperature rhythms reveal the phaseshifting behavior and plasticity of mammalian circadian oscillators. Genes Dev. 2012; 26:567-580.

25. James AB, Syed NH, Bordage S, Marshall J, Nimmo GA, Jenkins GI, Herzyk P, Brown JW , Nimmo HG. Alternative splicing mediates responses of the Arabidopsis circadian clock to temperature changes. Plant Cell. 2012; 24:961-981.

26. Orozco-Solis R, Sassone-Corsi P. Circadian clock: linking epigenetics to aging. Curr Opin Genet Dev. 2014; 26:66-72.

27. Partch CL, Green CB, Takahashi JS. Molecular architecture of the mammalian circadian clock. Trends Cell Biol. 2014; 24:90-99.

28. Ruan G-X, Gamble KL, Risner ML, Young LA, McMahon DG. Divergent roles of clock genes in retinal and suprachiasmatic nucleus circadian oscillators. PloS One. 2012; 7:e38985.

29. Yoo SH, Mohawk JA, Siepka SM, Shan Y, Huh SK, Hong HK, Kornblum I, Kumar V, Koike N, Xu M, Nussbaum J, Liu X, Chen Z, et al. Competing E3 ubiquitin ligases govern circadian periodicity by degradation of CRY in nucleus and cytoplasm. Cell. 2013; 152:1091-1105.

30. Gao P, Yoo SH, Lee KJ, Rosensweig C, Takahashi JS, Chen BP, Green CB. Phosphorylation of the cryptochrome $1 \mathrm{C}$-terminal tail regulates circadian period length. J Biol Chem. 2013; 288:35277-35286.

31. Wang Y, Kojetin D, Burris TP. Anti-proliferative actions of a synthetic REV-ERBalpha/beta agonist in breast cancer cells. Biochem Pharmacol. 2015; 96:315-322.

32. Zhang Y, Fang B, Emmett MJ, Damle M, Sun Z, Feng D, Armour SM, Remsberg JR, Jager J, Soccio RE, Steger DJ , Lazar MA. GENE REGULATION. Discrete functions of nuclear receptor Rev-erbalpha couple metabolism to the clock. Science. 2015; 348:1488-1492.

33. Curtis AM, Bellet MM, Sassone-Corsi P, O'Neill LA. Circadian clock proteins and immunity. Immunity. 2014; 40:178-186.

34. Nakahata Y, Sahar S, Astarita G, Kaluzova M, SassoneCorsi P. Circadian control of the NAD+ salvage pathway by CLOCK-SIRT1. Science. 2009; 324:654-657.

35. Nader N, Chrousos GP , Kino T. Circadian rhythm transcription factor CLOCK regulates the transcriptional activity of the glucocorticoid receptor by acetylating its hinge region lysine cluster: potential physiological implications. FASEB J. 2009; 23:1572-1583.

36. Hoffman AE, Yi CH, Zheng T, Stevens RG, Leaderer D, Zhang Y, Holford TR, Hansen J, Paulson J , Zhu Y. CLOCK in breast tumorigenesis: genetic, epigenetic, and transcriptional profiling analyses. Cancer Res. 2010; 70:1459-1468.

37. Kojima S, Shingle DL, Green CB. Post-transcriptional control of circadian rhythms. J Cell Sci. 2011; 124:311-320.

38. Beckwith EJ, Yanovsky MJ. Circadian regulation of gene 
expression: At the crossroads of transcriptional and posttranscriptional regulatory networks. Curr Opin Genet Dev. $2014 ; 27: 35-42$.

39. Mauvoisin D, Wang J, Jouffe C, Martin E, Atger F, Waridel P, Quadroni M, Gachon F, Naef F. Circadian clockdependent and -independent rhythmic proteomes implement distinct diurnal functions in mouse liver. Proc Natl Acad Sci U S A. 2014; 111:167-172.

40. Choudhary MK, Nomura Y, Wang L, Nakagami H, Somers DE. Quantitative Circadian Phosphoproteomic Analysis of Arabidopsis Reveals Extensive Clock Control of Key Components in Physiological, Metabolic, and Signaling Pathways. Mol Cell Proteomics. 2015; 14:2243-2260.

41. Uno K, Yamada $\mathrm{T}$, Ishigaki $\mathrm{Y}$, Imai J, Hasegawa $\mathrm{Y}$, Sawada S, Kaneko K, Ono H, Asano T, Oka Y ,Katagiri H. A hepatic amino acid/mTOR/S6K-dependent signalling pathway modulates systemic lipid metabolism via neuronal signals. Nat Commun. 2015; 6:7940.

42. Leontieva OV, Paszkiewicz GM, Blagosklonny MV. Comparison of rapamycin schedules in mice on high-fat diet. Cell Cycle. 2014; 13:3350-3356.

43. Khapre RV, Patel SA, Kondratova AA, Chaudhary A, Velingkaar N, Antoch MP, Kondratov RV. Metabolic clock generates nutrient anticipation rhythms in mTOR signaling. Aging (Albany NY). 2014; 6:675-689.

44. Khapre RV, Kondratova AA, Patel S, Dubrovsky Y, Wrobel M, Antoch MP , Kondratov RV. BMAL1-dependent regulation of the $\mathrm{mTOR}$ signaling pathway delays aging. Aging (Albany NY). 2014; 6:48-57.

45. Chaves I, van der Horst GT, Schellevis R, Nijman RM, Koerkamp MG, Holstege FC, Smidt MP , Hoekman MF. Insulin-FOXO3 signaling modulates circadian rhythms via regulation of clock transcription. Curr Biol. 2014; 24:12481255 .

46. Taniguchi H, Fernandez AF, Setien F, Ropero S, Ballestar E, Villanueva A, Yamamoto H, Imai K, Shinomura Y, Esteller M. Epigenetic inactivation of the circadian clock gene BMAL1 in hematologic malignancies. Cancer Res. 2009; 69:8447-8454.

47. Azzi A, Dallmann R, Casserly A, Rehrauer H, Patrignani A, Maier B, Kramer A, Brown SA. Circadian behavior is light-reprogrammed by plastic DNA methylation. Nat Neurosci. 2014; 17:377-382.

48. Yeh C-M, Shay J, Zeng T-C, Chou J-L, Huang TH-M, Lai H-C , Chan MW. Epigenetic silencing of ARNTL, a circadian gene and potential tumor suppressor in ovarian cancer. Int J Oncol. 2014; 45:2101-2107.

49. Bhatwadekar AD, Yan Y, Stepps V, Hazra S, Korah M, Bartelmez S, Chaqour B , Grant MB. miR-92a Corrects CD34+ Cell Dysfunction in Diabetes by Modulating Core Circadian Genes Involved in Progenitor Differentiation. Diabetes. 2015; 64:4226-4237.

50. DiTacchio L, Le HD, Vollmers C, Hatori M, Witcher M, Secombe J , Panda S. Histone lysine demethylase JARID1a activates CLOCK-BMAL1 and influences the circadian clock. Science. 2011; 333:1881-1885.

51. Nakahata Y, Kaluzova M, Grimaldi B, Sahar S, Hirayama J, Chen D, Guarente LP, Sassone-Corsi P. The NAD+dependent deacetylase SIRT1 modulates CLOCK-mediated chromatin remodeling and circadian control. Cell. 2008; 134:329-340.

52. Trauner M, Claudel T, Fickert P, Moustafa T, Wagner $\mathrm{M}$. Bile acids as regulators of hepatic lipid and glucose metabolism. Dig Dis. 2010; 28:220-224.

53. Li T, Chiang JY. Bile acids as metabolic regulators. Curr Opin Gastroenterol. 2015; 31:159-165.

54. Asher G, Sassone-Corsi P. Time for food: the intimate interplay between nutrition, metabolism, and the circadian clock. Cell. 2015; 161:84-92.

55. Mauvoisin D, Wang J, Jouffe C, Martin E, Atger F, Waridel P, Quadroni M, Gachon F, Naef F. Circadian clockdependent and-independent rhythmic proteomes implement distinct diurnal functions in mouse liver. Proc Natl Acad Sci U S A. 2014; 111:167-172.

56. Ramanathan $\mathrm{C}, \mathrm{Xu} \mathrm{H}$, Khan SK, Shen Y, Gitis PJ, Welsh DK, Hogenesch JB , Liu AC. Cell type-specific functions of period genes revealed by novel adipocyte and hepatocyte circadian clock models. PLoS Genet. 2014; 10:e1004244.

57. Rey G, Cesbron F, Rougemont J, Reinke H, Brunner M, Naef F. Genome-wide and phase-specific DNA-binding rhythms of BMAL1 control circadian output functions in mouse liver. PLoS Biol. 2011; 9:e1000595.

58. Barnea M, Chapnik N, Genzer Y, Froy O. The circadian clock machinery controls adiponectin expression. Mol Cell Endocrinol. 2015; 399:284-287.

59. Awazawa M, Ueki K, Inabe K, Yamauchi T, Kubota N, Kaneko K, Kobayashi M, Iwane A, Sasako T, Okazaki Y, Ohsugi M, Takamoto I, Yamashita S, et al. Adiponectin enhances insulin sensitivity by increasing hepatic IRS2 expression via a macrophage-derived IL-6-dependent pathway. Cell Metab. 2011; 13:401-412.

60. Barnea M, Madar Z, Froy O. High-fat diet delays and fasting advances the circadian expression of adiponectin signaling components in mouse liver. Endocrinology. 2009; 150:161-168.

61. Coomans CP, van den Berg SA, Lucassen EA, Houben T, Pronk AC, van der Spek RD, Kalsbeek A, Biermasz NR, Willems van Dijk K, Romijn JA, Meijer JH. The suprachiasmatic nucleus controls circadian energy metabolism and hepatic insulin sensitivity. Diabetes. 2013; 62:1102-1108.

62. Shi SQ, Ansari TS, McGuinness OP, Wasserman DH , Johnson $\mathrm{CH}$. Circadian disruption leads to insulin resistance and obesity. Curr Biol. 2013; 23:372-381.

63. Zhang D, Tong X, Arthurs B, Guha A, Rui L, Kamath A, Inoki K, Yin L. Liver clock protein bmall promotes de novo lipogenesis through insulin-mTORc2-akt signaling. J Biol Chem. 2014; 289:25925-25935. 
64. Tseng HL, Yang SC, Yang SH, Shieh KR. Hepatic circadian-clock system altered by insulin resistance, diabetes and insulin sensitizer in mice. PloS One. 2015; 10:e0120380.

65. Dallmann R, Weaver DR. Altered body mass regulation in male mPeriod mutant mice on high-fat diet. Chronobiol Int. 2010; 27:1317-1328.

66. Bur IM, Cohen-Solal AM, Carmignac D, Abecassis PY, Chauvet N, Martin AO, van der Horst GT, Robinson IC, Maurel P, Mollard P , Bonnefont X. The circadian clock components CRY1 and CRY2 are necessary to sustain sex dimorphism in mouse liver metabolism. J Biol Chem. 2009; 284:9066-9073.

67. Adamovich Y, Rousso-Noori L, Zwighaft Z, NeufeldCohen A, Golik M, Kraut-Cohen J, Wang M, Han X, Asher G. Circadian clocks and feeding time regulate the oscillations and levels of hepatic triglycerides. Cell Metab. 2014; 19:319-330.

68. Wang F, Zhang X, Wang J, Chen M, Fan N, Ma Q, Liu R, Wang R, Li X, Liu M. LGR4 acts as a link between the peripheral circadian clock and lipid metabolism in liver. J Mol Endocrinol. 2014; 52:133-143.

69. Green CB, Douris N, Kojima S, Strayer CA, Fogerty J, Lourim D, Keller SR , Besharse JC. Loss of Nocturnin, a circadian deadenylase, confers resistance to hepatic steatosis and diet-induced obesity. Proc Natl Acad Sci U S A. 2007; 104:9888-9893.

70. Kawai M , Rosen CJ. PPARgamma: a circadian transcription factor in adipogenesis and osteogenesis. Nat Rev Endocrinol. 2010; 6:629-636.

71. Cretenet G, Le Clech M, Gachon F. Circadian clockcoordinated $12 \mathrm{hr}$ period rhythmic activation of the IRE1 pathway controls lipid metabolism in mouse liver. Cell Metab. 2010; 11:47-57.

72. Xu J, Lloyd DJ, Hale C, Stanislaus S, Chen M, Sivits G, Vonderfecht S, Hecht R, Li YS, Lindberg RA, Chen JL, Jung DY, Zhang Z, et al. Fibroblast growth factor 21 reverses hepatic steatosis, increases energy expenditure, and improves insulin sensitivity in diet-induced obese mice. Diabetes. 2009; 58:250-259.

73. Estall JL, Ruas JL, Choi CS, Laznik D, Badman M, Maratos-Flier E, Shulman GI , Spiegelman BM. PGC1 negatively regulates hepatic FGF21 expression by modulating the heme/Rev-Erb axis. Proc Natl Acad Sci U S A. 2009; 106:22510-22515.

74. Sonoda J, Mehl IR, Chong L-W, Nofsinger RR and Evans RM. PGC-1 controls mitochondrial metabolism to modulate circadian activity, adaptive thermogenesis, and hepatic steatosis. Proc Natl Acad Sci U S A. 2007; 104:5223-5228.

75. Doi R, Oishi K, Ishida N. CLOCK regulates circadian rhythms of hepatic glycogen synthesis through transcriptional activation of Gys2. J Biol Chem. 2010; 285:22114-22121.

76. Ferrell JM and Chiang JY. Short-term circadian disruption impairs bile acid and lipid homeostasis in mice. CMGH Cell Mol Gastroenterol Hepatol. 2015; 1:664-677.

77. Han SS, Zhang R, Jain R, Shi H, Zhang L, Zhou G, Sangwung P, Tugal D, Atkins GB , Prosdocimo DA. Circadian control of bile acid synthesis by a KLF15-Fgf15 axis. Nat Commun. 2015; 6:8270.

78. Robles MS, Cox J, Mann M. In-vivo quantitative proteomics reveals a key contribution of post-transcriptional mechanisms to the circadian regulation of liver metabolism. Plos Genet. 2014; 10:e1004047.

79. Kim DH, Rhee JC, Yeo S, Shen R, Lee SK, Lee JW, Lee S. Crucial roles of mixed-lineage leukemia 3 and 4 as epigenetic switches of the hepatic circadian clock controlling bile acid homeostasis in mice. Hepatology. 2015; 61:1012-1023.

80. Zhou B, Zhang Y, Zhang F, Xia Y, Liu J, Huang R, Wang Y, Hu Y, Wu J, Dai C. CLOCK/BMAL1 regulates circadian change of mouse hepatic insulin sensitivity by SIRT1. Hepatology. 2014; 59:2196-2206.

81. Purushotham A, Schug TT, Xu Q, Surapureddi S, Guo X , Li X. Hepatocyte-specific deletion of SIRT1 alters fatty acid metabolism and results in hepatic steatosis and inflammation. Cell Metabol. 2009; 9:327-338.

82. Yang X, Downes M, Yu RT, Bookout AL, He W, Straume M, Mangelsdorf DJ , Evans RM. Nuclear receptor expression links the circadian clock to metabolism. Cell. 2006; 126:801-810.

83. Bugge A, Feng D, Everett LJ, Briggs ER, Mullican SE, Wang F, Jager J , Lazar MA. Rev-erb and Reverb coordinately protect the circadian clock and normal metabolic function. GenesDev. 2012; 26:657-667.

84. Cho H, Zhao X, Hatori M, Ruth TY, Barish GD, Lam MT, Chong L-W, DiTacchio L, Atkins AR, Glass CK. Regulation of circadian behaviour and metabolism by REVERB- [agr] and REV-ERB- [bgr]. Nature. 2012; 485:123127.

85. Gatfield D, Le Martelot G, Vejnar CE, Gerlach D, Schaad O, Fleury-Olela F, Ruskeepaa AL, Oresic M, Esau CC, Zdobnov EM, Schibler U. Integration of microRNA miR122 in hepatic circadian gene expression. Genes Dev. 2009; 23:1313-1326.

86. Kojima S, Gatfield D, Esau CC , Green CB. MicroRNA-122 modulates the rhythmic expression profile of the circadian deadenylase Nocturnin in mouse liver. PloS One. 2010; 5:e11264.

87. Alenghat T, Meyers K, Mullican SE, Leitner K, AdenijiAdele A, Avila J, Bucan M, Ahima RS, Kaestner KH , Lazar MA. Nuclear receptor corepressor and histone deacetylase 3 govern circadian metabolic physiology. Nature. 2008; 456:997-1000.

88. Feng D, Liu T, Sun Z, Bugge A, Mullican SE, Alenghat T, Liu XS , Lazar MA. A circadian rhythm orchestrated by histone deacetylase 3 controls hepatic lipid metabolism. Science. 2011; 331:1315-1319. 
89. Xu W, Hellerbrand C, Kohler UA, Bugnon P, Kan YW, Werner S and Beyer TA. The Nrf2 transcription factor protects from toxin-induced liver injury and fibrosis. Lab Invest. 2008; 88:1068-1078.

90. Cohen JC, Horton JD, Hobbs HH. Human fatty liver disease: old questions and new insights. Science. 2011; 332:1519-1523.

91. Davern TJ, Chalasani N, Fontana RJ, Hayashi PH, Protiva P, Kleiner DE, Engle RE, Nguyen H, Emerson SU, Purcell RH. Acute hepatitis E infection accounts for some cases of suspected drug-induced liver injury. Gastroenterology. 2011; 141:1665-1672.

92. Pellicoro A, Ramachandran P, Iredale JP, Fallowfield JA. Liver fibrosis and repair: immune regulation of wound healing in a solid organ. Nature Rev Immunol. 2014; 14:181-194.

93. Lan T, Kisseleva T, Brenner DA. Deficiency of NOX1 or NOX4 Prevents Liver Inflammation and Fibrosis in Mice through Inhibition of Hepatic Stellate Cell Activation. PloS One. 2015; 10:e129743.

94. Pekovic-Vaughan V, Gibbs J, Yoshitane H, Yang N, Pathiranage D, Guo B, Sagami A, Taguchi K, Bechtold D , Loudon A. The circadian clock regulates rhythmic activation of the NRF2/glutathione-mediated antioxidant defense pathway to modulate pulmonary fibrosis. Genes Dev. 2014; 28:548-560.

95. Touw D, Knox A, Smyth A. Population pharmacokinetics of tobramycin administered thrice daily and once daily in children and adults with cystic fibrosis. J Cyst Fibros. 2007; 6:327-333.

96. Chen P, Kakan X, Wang S, Dong W, Jia A, Cai C, Zhang J. Deletion of clock gene Per2 exacerbates cholestatic liver injury and fibrosis in mice. Exp Toxicol Pathol. 2013; 65:427-432.

97. Nguyen TT, Mattick JS, Yang Q, Orman MA, Ierapetritou MG, Berthiaume F, Androulakis IP. Bioinformatics analysis of transcriptional regulation of circadian genes in rat liver. BMC Bioinformatics. 2014; 15:83.

98. Hirao J, Niino N, Arakawa S, Shibata S, Mori K, Ando Y, Furukawa T, Sanbuissho A, Manabe S, Mori Y, Nishihara M. Circadian modulation of hepatic transcriptome in transgenic rats expressing human growth hormone. J Toxicol Sci. 2010; 35:673-685.

99. Hu Y, Spengler ML, Kuropatwinski KK, Comas M, Jackson M, Chernov MV, Gleiberman AS, Fedtsova N, Rustum YM, Gudkov AV. Selenium is a modulator of circadian clock that protects mice from the toxicity of a chemotherapeutic drug via upregulation of the core clock protein, BMAL1. Oncotarget. 2011; 2:1279-1290. doi: 10.18632/oncotarget.411.

100. Summa KC, Jiang P, Fitzpatrick K, Voigt RM, Bowers SJ, Forsyth CB, Vitaterna MH, Keshavarzian A, Turek FW. Chronic Alcohol Exposure and the Circadian Clock Mutation Exert Tissue-Specific Effects on Gene Expression in Mouse Hippocampus, Liver, and Proximal Colon. Alcohol, Clin Exp Res. 2015; 39:1917-1929.

101. Forsyth CB, Voigt RM, Burgess HJ, Swanson GR , Keshavarzian A. Circadian rhythms, alcohol and gut interactions. Alcohol. 2015; 49:389-398.

102. Summa KC, Voigt RM, Forsyth CB, Shaikh M, Cavanaugh K, Tang Y, Vitaterna MH, Song S, Turek FW, Keshavarzian A. Disruption of the Circadian Clock in Mice Increases Intestinal Permeability and Promotes AlcoholInduced Hepatic Pathology and Inflammation. PloS One. 2013; 8:e67102.

103. Kudo T, Tamagawa T, Shibata S. Effect of chronic ethanol exposure on the liver of Clock-mutant mice. J Circadian Rhythms. 2009; 7:4.

104. Wang T, Yang P, Zhan Y, Xia L, Hua Z, Zhang J. Deletion of circadian gene Per1 alleviates acute ethanol-induced hepatotoxicity in mice. Toxicology. 2013; 314:193-201.

105. Richards J, Welch AK, Barilovits SJ, All S, Cheng KY, Wingo CS, Cain BD, Gumz ML. Tissue-specific and timedependent regulation of the endothelin axis by the circadian clock protein Per1. Life Sci. 2014; 118:255-262.

106. Yayla M, Halici Z, Unal B, Bayir Y, Akpinar E, Gocer F. Protective effect of Et-1 receptor antagonist bosentan on paracetamol induced acute liver toxicity in rats. Eur J Pharmacol. 2014; 726:87-95.

107. Kwok W and Clemens MG. Rho-kinase activation contributes to Lps-induced impairment of endothelial nitric oxide synthase activation by endothelin-1 in cultured hepatic sinusoidal endothelial cells. Shock. 2014; 42:554561.

108. Kitoh Y, Ohmori M, Araki N, Miyashita F, Ando H, Kobayashi E, Sogawa N and Fujimura A. Dosing-timedependent differences in lipopolysaccharide-induced liver injury in rats. Chronobiol Int. 2005; 22:987-996.

109. Kakan X, Chen P ,Zhang J. Clock gene mPer2 functions in diurnal variation of acetaminophen induced hepatotoxicity in mice. Exp Toxicol Pathol. 2011; 63:581-585.

110. Chen P, Kakan X, Zhang J. Altered circadian rhythm of the clock genes in fibrotic livers induced by carbon tetrachloride. FEBS Lett. 2010; 584:1597-1601.

111. Chen P, Li C, Pang W, Zhao Y, Dong W, Wang S, Zhang J. The protective role of Per2 against carbon tetrachlorideinduced hepatotoxicity. Am J Pathol. 2009; 174:63-70.

112. Bruckner JV, Ramanathan R, Lee KM and Muralidhara S. Mechanisms of circadian rhythmicity of carbon tetrachloride hepatotoxicity. J Pharmacol Exp Ther. 2002; 300:273-281.

113. Chen P, Han Z, Yang P, Zhu L, Hua Z, Zhang J. Loss of clock gene mPer2 promotes liver fibrosis induced by carbon tetrachloride. Hepatol Res. 2010; 40:1117-1127.

114. Liu X, Hu H, Yin JQ. Therapeutic strategies against TGFsignaling pathway in hepatic fibrosis. Liver Int. 2006; 26:822.

115. Sato F, Sato H, Jin D, Bhawal UK, Wu Y, Noshiro M, 
Kawamoto T, Fujimoto K, Seino H, Morohashi S. Smad3 and Snail show circadian expression in human gingival fibroblasts, human mesenchymal stem cell, and in mouse liver. Biochem Biophys Res Commun. 2012; 419:441-446.

116. Thomas M, Burk O, Klumpp B, Kandel BA, Damm G, Weiss TS, Klein K, Schwab M and Zanger UM. Direct Transcriptional Regulation of Human Hepatic Cytochrome P450 3A4 (CYP3A4) by Peroxisome Proliferator-Activated Receptor Alpha (PPAR). Mol Pharmacol. 2013; 83:709718.

117. Borengasser SJ, Kang P, Faske J, Gomez-Acevedo H, Blackburn ML, Badger TM, Shankar K. High fat diet and in utero exposure to maternal obesity disrupts circadian rhythm and leads to metabolic programming of liver in rat offspring. PloS One. 2014; 9:e84209.

118. Iurisci I, Filipski E, Sallam H, Harper F, Guettier C, Maire I, Hassan M, Iacobelli S and Levi F. Liver circadian clock, a pharmacologic target of cyclin-dependent kinase inhibitor seliciclib. Chronobiol Int. 2009; 26:1169-1188.

119. Yin L, Wu N, Curtin JC, Qatanani M, Szwergold NR, Reid RA, Waitt GM, Parks DJ, Pearce KH, Wisely GB. Reverb, a heme sensor that coordinates metabolic and circadian pathways. Science. 2007; 318:1786-1789.

120. Li T, Eheim AL, Klein S, Uschner FE, Smith AC, BrandonWarner E, Ghosh S, Bonkovsky HL, Trebicka J , Schrum LW. Novel role of nuclear receptor Rev-erbalpha in hepatic stellate cell activation: potential therapeutic target for liver injury. Hepatology. 2014; 59:2383-2396.

121. Wang J, Yin L and Lazar MA. The orphan nuclear receptor Rev-erb alpha regulates circadian expression of plasminogen activator inhibitor type 1. J Biol Chem. 2006; 281:33842-33848.

122. Wang H, Zhang Y, Heuckeroth RO. PAI-1 deficiency reduces liver fibrosis after bile duct ligation in mice through activation of tPA. FEBS Lett. 2007; 581:3098-3104.

123. Oishi K, Ohkura N, Wakabayashi M, Shirai H, Sato K, Matsuda J, Atsumi G, Ishida N. CLOCK is involved in obesityinduced disordered fibrinolysis in ob/ob mice by regulating PAI1 gene expression. J Thromb Haemost. 2006; 4:1774-1780.

124. Oishi K, Miyazaki K, Uchida D, Ohkura N, Wakabayashi M, Doi R, Matsuda J , Ishida N. PERIOD2 is a circadian negative regulator of PAI-1 gene expression in mice. $\mathrm{J}$ Mol Cell Cardiol. 2009; 46:545-552.

125. GerhartHines Z and Lazar M. Reverb and the circadian transcriptional regulation of metabolism. Diabete, Obes Metab. 2015; 17:12-16.

126. Curtis AM, Fagundes CT, Yang G, Palsson-McDermott EM, Wochal P, McGettrick AF, Foley NH, Early JO, Chen L, Zhang H, Xue C, Geiger SS, Hokamp K, et al. Circadian control of innate immunity in macrophages by miR-155 targeting Bmal1. Proc Natl Acad Sci U S A. 2015; 112:7231-7236.

127. Seki E, De Minicis S, Österreicher CH, Kluwe J, Osawa Y,
Brenner DA, Schwabe RF. TLR4 enhances TGF- signaling and hepatic fibrosis. Nat Med. 2007; 13:1324-1332.

128. Mandrekar P, Szabo G. Signalling pathways in alcoholinduced liver inflammation. J Hepatol. 2009; 50:1258-1266.

129. Heymann F, Trautwein C and Tacke F. Monocytes and macrophages as cellular targets in liver fibrosis. Inflamm AllergyDrug Targets. 2009; 8:307-318.

130. Bruix J, Gores GJ , Mazzaferro V. Hepatocellular carcinoma: clinical frontiers and perspectives. Gut. 2014; 63:844-855.

131. Singh S, Singh PP, Roberts LR , Sanchez W. Chemopreventive strategies in hepatocellular carcinoma. Nat Rev Gastroenterol Hepatol. 2014; 11:45-54.

132. Mazzoccoli G, Vinciguerra M, Oben J, Tarquini R and De Cosmo S. Non-alcoholic fatty liver disease: the role of nuclear receptors and circadian rhythmicity. Liver Int. 2014; 34:1133-1152.

133. Sabath E, Báez-Ruiz A and Buijs R. Non-alcoholic fatty liver disease as a consequence of autonomic imbalance and circadian desynchronization. Obes Rev. 2015; 16:871-882.

134. Tan X-M, Ye H, Yang K, Chen D, Wang Q-Q, Tang H and Zhao N-B. Circadian variations of clock gene Per2 and cell cycle genes in different stages of carcinogenesis in golden hamster buccal mucosa. Sci Rep. 2015; 5:9997.

135. Wang Y, Kojetin D, Burris TP. Anti-proliferative actions of a synthetic REV-ERB/ agonist in breast cancer cells. Biochem Pharmacol. 2015; 96:315-322.

136. Hua H, Wang Y, Wan C, Liu Y, Zhu B, Yang C, Wang X, Wang Z, Cornelissen-Guillaume G, Halberg F. Circadian gene mPer2 overexpression induces cancer cell apoptosis. Cancer Sci. 2006; 97:589-596.

137. Cadenas C, van de Sandt L, Edlund K, Lohr M, Hellwig B, Marchan R, Schmidt M, Rahnenführer J, Oster H, Hengstler JG. Loss of circadian clock gene expression is associated with tumor progression in breast cancer. Cell Cycle. 2014; 13:3282-3291.

138. Zeng Z-1, Luo H-y, Yang J, Wu W-j, Chen D-1, Huang P, $\mathrm{Xu}$ R-h. Overexpression of the circadian clock gene Bmall increases sensitivity to oxaliplatin in colorectal cancer. Clin Cancer Res. 2014; 20:1042-1052.

139. Wang Y, Qian R, Sun N, Lu C, Chen Z, Hua L. Circadian gene hClock enhances proliferation and inhibits apoptosis of human colorectal carcinoma cells in vitro and in vivo. Mol Med Rep. 2015; 11:4204-4210.

140. Zhanfeng N, Yanhui L, Zhou F, Shaocai H, Guangxing L ,Hechun X. Circadian genes Per1 and Per2 increase radiosensitivity of glioma in vivo. Oncotarget. 2015; 6:9951-9958. doi: 10.18632/oncotarget.3179.

141. Hu ML, Yeh KT, Lin PM, Hsu CM, Hsiao HH, Liu YC, Lin HY, Lin SF , Yang MY. Deregulated expression of circadian clock genes in gastric cancer. BMC Gastroenterol. 2014; 14:67.

142. Couto P, Miranda D, Vieira R, Vilhena A, De Marco L, Bastos-Rodrigues L. Association between CLOCK, PER3 
and CCRN4L with non-small cell lung cancer in Brazilian patients. Mol Med Rep. 2014; 10:435-440.

143. Zhu Y, Stevens RG, Hoffman AE, Fitzgerald LM, Kwon EM, Ostrander EA, Davis S, Zheng T , Stanford JL. Testing the circadian gene hypothesis in prostate cancer: a population-based case-control study. Cancer Res. 2009; 69:9315-9322.

144. Yeh C-T, Lu S-C, Tseng I-C, Lai H-Y, Tsao M-L, Huang S-F , Liaw Y-F. Antisense overexpression of BMAL2 enhances cell proliferation. Oncogene. 2003; 22:5306-5314.

145. Kruse RL, Kramer JR, Tyson GL, Duan Z, Chen L, ElSerag HB , Kanwal F. Clinical outcomes of hepatitis B virus coinfection in a United States cohort of hepatitis C virusinfected patients. Hepatology. 2014; 60:1871-1878.

146. Yang SL, Yu C, Jiang JX, Liu LP, Fang X and Wu C. Hepatitis B virus $\mathrm{X}$ protein disrupts the balance of the expression of circadian rhythm genes in hepatocellular carcinoma. Oncol Lett. 2014; 8:2715-2720.

147. Benegiamo G, Mazzoccoli G, Cappello F, Rappa F, Scibetta N, Oben J, Greco A, Williams R, Andriulli A, Vinciguerra M. Mutual antagonism between circadian protein period 2 and hepatitis $\mathrm{C}$ virus replication in hepatocytes. PloS One. 2013; 8:e60527.

148. Lee JH and Sancar A. Regulation of apoptosis by the circadian clock through NF-kappaB signaling. Proc Natl Acad Sci U S A. 2011; 108:12036-12041.

149. Lin YM, Chang JH, Yeh KT, Yang MY, Liu TC, Lin SF, Su WW, Chang JG. Disturbance of circadian gene expression in hepatocellular carcinoma. Mol Carcinog. 2008; 47:925933.

150. Gery S, Komatsu N, Kawamata N, Miller CW, Desmond J, Virk RK, Marchevsky A, McKenna R, Taguchi H, Koeffler HP. Epigenetic silencing of the candidate tumor suppressor gene Per1 in non-small cell lung cancer. Clin Cancer Res. 2007; 13:1399-1404.

151. Cui M, Zheng M, Sun B, Wang Y, Ye L, Zhang X. A long noncoding RNA perturbs the circadian rhythm of hepatoma cells to facilitate hepatocarcinogenesis. Neoplasia. 2015; 17:79-88.

152. Shin S, Wolgamott L, Roux PP, Yoon SO. Casein kinase 1epsilon promotes cell proliferation by regulating mRNA translation. Cancer Res. 2014; 74:201-211.

153. Lu JW, Liao CY, Yang WY, Lin YM, Jin SL, Wang $\mathrm{HD}$, Yuh CH. Overexpression of endothelin 1 triggers hepatocarcinogenesis in zebrafish and promotes cell proliferation and migration through the AKT pathway. PloS One. 2014; 9:e85318.

154. Lu JW, Hsia Y, Yang WY, Lin YI, Li CC, Tsai TF, Chang KW, Shieh GS, Tsai SF, Wang HD, Yuh CH. Identification of the common regulators for hepatocellular carcinoma induced by hepatitis B virus X antigen in a mouse model. Carcinogenesis. 2012; 33:209-219.

155. Huisman SA, Oklejewicz M, Ahmadi AR, Tamanini F, Ijzermans JN, van der Horst GT, de Bruin RW. Colorectal liver metastases with a disrupted circadian rhythm phase shift the peripheral clock in liver and kidney. Int J Cancer. 2015; 136:1024-1032.

156. Yu C, Yang SL, Fang X, Jiang JX, Sun CY, Huang T. Hypoxia disrupts the expression levels of circadian rhythm genes in hepatocellular carcinoma. Mol Med Rep. 2015; 11:4002-4008.

157. Zhao B, Lu J, Yin J, Liu H, Guo X, Yang Y, Ge N, Zhu $\mathrm{Y}$, Zhang $\mathrm{H}$, Xing J. A functional polymorphism in PER3 gene is associated with prognosis in hepatocellular carcinoma. Liver Int. 2012; 32:1451-1459.

158. Davidson AJ, Straume M, Block GD, Menaker M. Daily timed meals dissociate circadian rhythms in hepatoma and healthy host liver. Int J Cancer. 2006; 118:1623-1627.

159. Gorbacheva VY, Kondratov RV, Zhang R, Cherukuri S, Gudkov AV, Takahashi JS , Antoch MP. Circadian sensitivity to the chemotherapeutic agent cyclophosphamide depends on the functional status of the CLOCK/BMAL1 transactivation complex. Proce NatlAcad Sci U S A. 2005; 102:3407-3412.

160. Filipski E, Subramanian P, Carriere J, Guettier C, Barbason H, Levi F. Circadian disruption accelerates liver carcinogenesis in mice. Mutat Res. 2009; 680:95-105.

161. Ferrell JM , Chiang JY. Circadian rhythms in liver metabolism and disease. Acta PharmSin B. 2015; 5:113122.

162. Johnson BP, Walisser JA, Liu Y, Shen AL, McDearmon EL, Moran SM, McIntosh BE, Vollrath AL, Schook AC, Takahashi JS , Bradfield CA. Hepatocyte circadian clock controls acetaminophen bioactivation through NADPHcytochrome P450 oxidoreductase. Proc Natl Acad Sci U S A. $2014 ; 111: 18757-18762$.

163. Maglione JE, Nievergelt CM, Parimi N, Evans DS, AncoliIsrael S, Stone KL, Yaffe K, Redline S, Tranah GJ. Study of Osteoporotic Fractures in W and Osteoporotic Fractures in Men Study Research G. Associations of PER3 and RORA Circadian Gene Polymorphisms and Depressive Symptoms in Older Adults. Am J Geriatr Psychiatry. 2015; 23:10751087.

164. Yamaguchi M, Kotani K, Tsuzaki K, Takagi A, Motokubota N, Komai N, Sakane N, Moritani T, Nagai N. Circadian rhythm genes CLOCK and PER3 polymorphisms and morning gastric motility in humans. PloS One. 2015; 10:e0120009.

165. Padmanabhan K, Robles MS, Westerling T, Weitz CJ. Feedback regulation of transcriptional termination by the mammalian circadian clock PERIOD complex. Science. 2012; 337:599-602.

166. Mehra A, Baker CL, Loros JJ , Dunlap JC. Post-translational modifications in circadian rhythms. Trends in biochemical sciences. 2009; 34:483-490. 